\title{
Prevalence of Dyslipidaemia and Pre-Diabetes Among Women with Polycystic Ovary Syndrome (PCOS): Do We Overestimate Cardiovascular Risk?
}

Authors

Krzysztof C. Lewandowski ${ }^{1,2}$, Justyna Płusajska², Wojciech Horzelski³ ${ }^{3}$ Andrzej Lewiński ${ }^{1,2}$

Affiliations

1 Department of Endocrinology and Metabolic Diseases, Medical University of Lodz, Lodz, Poland

2 Department of Endocrinology and Metabolic Diseases, Polish Mother's Memorial Hospital - Research Institute, Lodz, Poland

3 Faculty of Mathematics and Computer Science, University of Lodz, Lodz, Poland

Key words androgens, insulin resistance, glucose intolerance dyslipidaemia, PCOS

received $\quad 11.12 .2018$

accepted 08.04.2019

Bibliography

DOI https://doi.org/10.1055/a-0896-4144

Published online: 10.5.2019

Horm Metab Res 2019; 51: 539-545

(c) Georg Thieme Verlag KG Stuttgart · New York

ISSN 0018-5043

Correspondence

Prof. Andrzej Lewinski MD, PhD

Department of Endocrinology and Metabolic Diseases, Polish Mother's Memorial Hospital - Research Institute, Rzgowska St. 281/289,

93-338 Lodz,

Poland

Tel.: + 48/42/271 11 41, Fax: + 48/42/271 1140

alewin@csk.umed.lodz.pl

\section{ABSTRACT}

PCOS is widely accepted as associated with an increased cardiovascular risk, however, without convincing evidence of an increased cardiovascular mortality. We assessed prevalence of obesity, glucose intolerance, and dyslipidaemia in 490 women with PCOS, aged $24.75 \pm 8.05$ years, diagnosed according to the Rotterdam consensus criteria. Fifty-two percent of women had $\mathrm{BMI}<26 \mathrm{~kg} / \mathrm{m}^{2}, 81.8 \%$ had total cholesterol $<200 \mathrm{mg} / \mathrm{dl}$, $82.8 \%$ had LDL cholesterol $<130 \mathrm{mg} / \mathrm{dl}(48.3 \%<100 \mathrm{mg} / \mathrm{dl})$, $81.4 \%$ had triglycerides $<150 \mathrm{mg} / \mathrm{dl}, 96.08 \%$ had fasting glucose $<100 \mathrm{mg} / \mathrm{dl}, 90.3 \%$ had glucose $<140 \mathrm{mg} / \mathrm{dl}$ at $120^{\prime}$ of OGTT. The most frequent abnormality was low HDL cholesterol, as only $33.9 \%$ had LDL $>60 \mathrm{mg} / \mathrm{dl}$. Combination of several risk factors related to dyslipidaemia was, however, relatively rare, for example, a combination of raised total cholesterol and LDL cholesterol was present only in $2.9 \%$ of subjects. An increase in BMI, total cholesterol, LDL-cholesterol, and glucose concentrations at $120^{\prime}$ of OGTT was more pronounced in women, who had raised concentrations of at least two androgens ( $n=172,35.1 \%$ ), yet there was no increase in insulin resistance parameters, that is, HOMA-IR, QUICKI, McAuley, or Belfiore index. Contrary to common belief, over $50 \%$ of women with PCOS have normal body weight, and with exception of lower HDL cholesterol, most have no significant dyslipidaemia or glucose intolerance. Women with normal or borderline abnormal androgens, who form the majority of PCOS subjects, seem to have more healthy metabolic profile. This might be one of the reasons for the absence of evidence of an increased CV mortality in women with PCOS.

\section{Introduction}

Polycystic ovary syndrome (PCOS) is the most common endocrinopathy of women in reproductive age, that is characterized by menstrual irregularities, hyperandrogenism/hyperandrogenaemia, insulin resistance, and fertility problems, though the extent of these abnormalities in individual patients is highly variable [1]. Furthermore, there is evidence of an increased prevalence of cardiovascular risk factors in PCOS that warrants active screening [2,3]. Yet, despite the fact that women with polycystic ovary syndrome have higher prevalence of obesity, abdominal fat distribution, dyslipidaemia, and deterioration of glucose metabolism, the increased prevalence of cardiovascular diseases is not proven [4-5]. Taking into account this paradox we have decided to assess the prevalence of obesity, dyslipidaemia, and glucose tolerance in women diagnosed with PCOS at the Department of Endocrinology and Metabolic Diseases of the Polish Mother's Memorial Hospital - Research Institute in Lodz. 


\section{Subjects and Methods}

The study included 490 women aged 25.02 years \pm 7.9 (mean \pm SD), BMI $26.8 \pm 7.01 \mathrm{~kg} / \mathrm{m}^{2}$ who underwent investigations for irregular periods, hirsutism, or biochemical hyperandrogenism in the Department of Endocrinology and Metabolic Diseases, The Medical University of Lodz and Polish Mother's Memorial Hospital - Research Institute in Lodz, Poland (between 2013 and 2016). In all subjects a diagnosis of PCOS was established according to the Rotterdam consensus criteria [6]. The studied population was almost entirely of Caucasian origin. All women were subjected to an identical investigation protocol that included hormonal assessment (TSH, free T4 and free T3, prolactin, total testosterone, androstenedione, DHEAS, 17-hydroxyprogesterone, cortisol after dexamethasone suppression test, fasting blood lipids, and intravaginal pelvic ultrasound). All subjects also underwent glucose and insulin measurements during $75 \mathrm{gram}$ oral glucose tolerance test (OGTT), where measurements were performed at 0,60 , and $120 \mathrm{~min}$. If clinically indicated, additional tests (e. g., IGF-I, growth hormone during OGTT, 17-hydroxyprogesterone measurements after $250 \mu \mathrm{g}$ of Synacthen, $24 \mathrm{~h}$ prolactin secretion profiles) were performed. Exclusion criteria included known type $2(n=3)$ or type 1 diabetes $(n=1)$ as contraindication for an OGTT, as well as conditions that are necessary to be ruled out in order to establish a diagnosis of PCOS, such as hypopituitarism, hyperprolactinaemia, acromegaly, Cushing's syndrome, premature ovarian failure, androgen secreting tumours, secondary amenorrhoea due to eating disorders, and all forms of congenital adrenal hyperplasia. All investigations were performed in the early follicular phase of either a spontaneous cycle, or after induction of the menstrual bleeding with progestagen [usually dydrogesterone (Duphaston ${ }^{\circledR}$ ) $10 \mathrm{mg}$ twice a day for 10 days].

In all investigated women, we also performed an assessment of insulin resistance according to the Insulin Resistance (Belfiore) Index, HOMA-IR, QUICKI and McAuley indices. Insulin Resistance Index (IRI), also known as Belfiore index, was calculated from changes of glycaemia and insulinaemia during a 75 gram oral glucose tolerance test (OGTT) according to the method described by Belfiore et al. [7]. IRI was calculated by the formula: ISI $\left.\right|_{(\mathrm{Gly})}=2 /[1 /(\mathrm{INSp} \times$ $\mathrm{GLYp})]+1$, where INSp and GLYp are the measured insulin and glycaemic areas. In normal subjects ISI (gly) are always around 1 , with maximal variations between 0 and 2 . This method is based on changes of glycaemia and insulinaemia during OGTT. According some authors the assessment of free fatty acids (FFAs) during OGTT is equally effective for the purpose of calculation of the IRI [7].

HOMA-IR index was calculated according to the formula: HOMA-IR $=[$ fasting glucose $](\mathrm{mmol} / \mathrm{I}) \times[$ fasting insulin $](\mu \mathrm{U} / \mathrm{ml}) / 22.5)$ [8]. QUICKI index was calculated according to the formula: QUICKI $=1 /\left[\log \left(I_{0}\right)+\log \left(G_{0}\right)\right.$, where $I_{0}$ denotes fasting insulin, and glucose $\left[\mathrm{G}_{0}\right.$ denotes fasting glucose] [9].

McAuley index was calculated according to the formula: Mff$\mathrm{m} / \mathrm{I}=\mathrm{e}\left[2.63-0.28 \ln \left(\mathrm{I}_{0}\right)-031 \ln \left(\mathrm{TAG}_{0}\right)\right]$, where $\mathrm{I}_{0}$ denotes fasting insulin, while $\mathrm{TAG}_{0}$ denotes fasting triglyceride concentrations [10]. The authors of the latter model [10], claim that in the multivariate model, inclusion of fasting triglycerides increases sensitivity of the model to assess IR even better than HOMA, fasting insulin or fasting insulin-to-glucose ratio.
Due to limitations of IR assessment based on fasting values, patients with known type 2 diabetes, according to high fasting blood glucose criterion (glucose concentrations $>7.0 \mathrm{mmol} / \mathrm{l}$ ) were not included into the study.

The prevalence of dyslipidaemia was assessed according to the criteria described by American Academy of Clinical Endocrinologists [11]. Interpretation of the results of 75 gram oral glucose tolerance test (OGTT) was performed according to the guidelines of the Polish Diabetes Society [12].

The study was approved by the Ethics Committee of the Polish Mother's Memorial Hospital - Research Institute. Consent has been obtained from each patient after full explanation of the purpose and nature of all procedures used.

Statistical analysis was performed by the means of MedClac software version 16.4.3. Data distribution assessment was performed by the means of D'Agostino-Pearson test. Two group comparison was performed by the means of Mann-Whitney test, while oneway ANOVA was employed for multiple group comparisons. Correlation analysis was performed with Spearman's coefficient of rank correlation.

\section{Results}

Distribution of patients according to BMI and lipid concentrations are presented in $>$ Table 1 . Over half of our patients ( $51.6 \%$ ) of patients had BMI below $26 \mathrm{~kg} / \mathrm{m}^{2}$. It should be noted that almost half of patients $(48.3 \%$ ) of patients had LDL cholesterol concentrations below $100 \mathrm{mg} / \mathrm{dl}(82.8 \%<130 \mathrm{mg} / \mathrm{dl})$, while relatively few had lipid concentrations in the highest risk category, for instance only 22 out of 490 (4.5\%) had total cholesterol concentrations above $240 \mathrm{mg} / \mathrm{dl}$. In contrast $81.8 \%$ had total cholesterol concentrations $<200 \mathrm{mg} / \mathrm{dl}$. The exception was HDL cholesterol concentration, where only $33.9 \%$ had $\mathrm{HDL}$ cholesterol concentrations above $60 \mathrm{mg} / \mathrm{dl}$.

Coexistence of several abnormal lipid parameters, defined as combination of total cholesterol (TC) concentrations $>240 \mathrm{mg} / \mathrm{dl}$, LDL-cholesterol $>160 \mathrm{mg} / \mathrm{dl}$, HDL-cholesterol $<50 \mathrm{mg} / \mathrm{dl}$, or triglycerides (TC) $>200 \mathrm{mg} / \mathrm{dl}$, was relatively rare. The most common abnormality was a combination of raised triglycerides and low HDL cholesterol ( $n=30,6.22 \%)$, but the prevalence of over combinations was much less common (e. g., raised total cholesterol and raised LDL concentrations, or raised total cholesterol and low HDL cholesterol were both present only 14 women $(2.9 \%)$. Combinations of other risk factors were less common, while combination of three risk factors ranged from $0.82 \%(T G \& L D L \& H D L, n=4)$ to $1.65 \%$ (TC \& LDL \& HDL, $n=8$ ). Only four subjects $(0.82 \%$ ) had simultaneous combinations of four abnormal lipid parameters (TC \& TG \& LDL \& HDL). Progressive worsening of the lipid profile was observed with an increase in BMI ( $\bullet$ Fig. 1a-d), though even in the group with $\mathrm{BMI}>30 \mathrm{~kg} / \mathrm{m}^{2}$, with exception of $\mathrm{HDL}$ cholesterol, mean lipid concentrations still remained within the reference range. > Fig. 1

During OGTT 19 patients (3.97\%) were found to have impaired fasting glucose (i. e., glucose concentrations 5.56 to $7.0 \mathrm{mmol} / \mathrm{l}$ ), 42 patients $(8.78 \%$ ) were found to have impaired glucose tolerance (i. e., glucose concentration 7.0 to $11.1 \mathrm{mmol} / \mathrm{l}$ at $120 \mathrm{~min}$ of OGTT), while 5 patients $(1.04 \%$ ) were found to have frank diabetes 
- Table 1 Distribution of body mass index (BMI) and lipid parameters in 490 women with PCOS.

\begin{tabular}{|c|c|c|c|c|c|}
\hline & & n (\%) & Mean & SD & SEM \\
\hline \multirow[t]{4}{*}{ BMI } & All & 490 & 27.26 & 7.17 & 0.32 \\
\hline & $<26 \mathrm{~kg} / \mathrm{m}^{2}$ & $253(51.6 \%)$ & 21.53 & 2.49 & 0.16 \\
\hline & $26-30 \mathrm{~kg} / \mathrm{m}^{2}$ & $78(15.9 \%)$ & 27.66 & 1.05 & 0.12 \\
\hline & $\geq 30 \mathrm{~kg} / \mathrm{m}^{2}$ & $159(32.4 \%)$ & 35.83 & 21.15 & 0.36 \\
\hline \multirow[t]{4}{*}{ Total cholesterol (mg/dl) } & All & 490 & 170.5 & 35.0 & 35.0 \\
\hline & $<200 \mathrm{mg} / \mathrm{dl}$ & $401(81.85)$ & 158.3 & 24.4 & 1.21 \\
\hline & $200-239 \mathrm{mg} / \mathrm{dl}$ & $67(13.7 \%)$ & 214.7 & 11.4 & 1.3 \\
\hline & $\geq 240 \mathrm{mg} / \mathrm{dl}$ & $22(4.5 \%)$ & 255.3 & 13.6 & 2.9 \\
\hline \multirow[t]{5}{*}{ LDL-cholesterol (mg/dl) } & All & 490 & 102 & 30.7 & 1.4 \\
\hline & $<100 \mathrm{mg} / \mathrm{dl}$ & $237(48.4 \%)$ & 78.9 & 15.6 & 1.0 \\
\hline & $100-129 \mathrm{mg} / \mathrm{dl}$ & $169(34.5 \%)$ & 113.1 & 8.4 & 0.7 \\
\hline & $130-159 \mathrm{mg} / \mathrm{dl}$ & $60(12.25)$ & 141.9 & 9.3 & 1.2 \\
\hline & $\geq 160 \mathrm{mg} / \mathrm{dl}$ & $24(4.9 \%)$ & 178.3 & 17.3 & 3.6 \\
\hline \multirow[t]{4}{*}{ HDL-cholesterol (mg/dl) } & All & 490 & 53.0 & 16.4 & 0.74 \\
\hline & $\geq 60 \mathrm{mg} / \mathrm{dl}$ & $166(33.9 \%)$ & 70.6 & 13.6 & 1.07 \\
\hline & $50-59 \mathrm{mg} / \mathrm{dl}$ & 96 (19.6\%) & 54.0 & 8.36 & 0.29 \\
\hline & $<50 \mathrm{mg} / \mathrm{dl}$ & $228(46.5 \%)$ & 40.0 & 6.9 & 0.4 \\
\hline \multirow[t]{4}{*}{ Triglycerides } & All & 490 & 107.8 & 75.21 & 3.41 \\
\hline & $<150 \mathrm{mg} / \mathrm{dl}$ & 399 (81.4\%) & 83.78 & 30.31 & 1.52 \\
\hline & $150-199 \mathrm{mg} / \mathrm{dl}$ & $56(11.4 \%)$ & 170.4 & 15.56 & 2.09 \\
\hline & $\geq 200 \mathrm{mg} / \mathrm{dl}$ & $35(7.15)$ & 283.3 & 158.38 & 26.77 \\
\hline
\end{tabular}

(glucose concentrations $>11.1 \mathrm{mmol} / \mathrm{l}$ at $120 \mathrm{~min}$ of OGTT). Four of these patients were also found to have simultaneously impaired fasting glucose. Coexistence of both impaired fasting glucose and impaired glucose tolerance was observed in $8(1.67 \%)$ patients.

In regression analysis, insulin resistance parameters correlated with lipids and testosterone concentrations ( $\triangleright$ Table 2 ), but in a multivariate analysis, BMI was found to be strongest determinant of both lipid and androgen status.

In the second part of the analysis, we stratified our patients according to their androgen status, into those with all androgens within the reference range, raised concentration of at least one androgen (total testosterone, androstenenedione or DHEAS), and raise concentrations of two or three androgens ( $\vee$ Table 3 ). We observed a significant increase in BMI, LDL cholesterol, and glucose concentrations with increasing hyperandrogenaemia. There was, however, no significant increase in other parameters, while mean glucose levels at 120 min of OGTT remained within the reference range.

\section{Discussion}

As mentioned above, PCOS remained the most common endocrinopathy of women of reproductive age [13]. In Poland this condition is usually diagnosed according to the Rotterdam consensus criteria [6], and is linked with an increased prevalence of cardiovascular disease risk factors [14-17], yet without clear evidence of an increased cardiovascular mortality [18-20]. Such a situation leads to an ongoing controversy $[17,20]$.
Our study, based on a large group of women with PCOS, diagnosed according to the uniform criteria in one centre, showed that over $50 \%$ of women with PCOS have normal BMI, while great majority (81.8\%) had total cholesterol or triglycerides $(81.4 \%)$ within the reference range. Also the prevalence of both type 2 diabetes $(1.04 \%$ ) or impaired fasting glucose $(3.97 \%$ ) was relatively low, with a slightly higher prevalence of impaired glucose tolerance ( $8.78 \%$ ). It is worthwhile to note that even though the prevalence of type 2 diabetes and glucose intolerance is higher in PCOS than in general population [21], the prevalence of type 2 diabetes is not increased in non-obese women with $P C O S$ [22], which in our case constitute half of our patients.

In our opinion, the prevalence of dyslipidaemia and glucose intolerance in our PCOS cohort might be even overestimated, as our cohort consisted entirely of women who were hospitalized because of PCOS-related problems (mostly oligo-/amenorrhoea). We can therefore expect that prevalence of dislipidaemia or glucose intolerance was likely to be higher in comparison to women with milder phenotypes, who were less likely in hospital care. It should be also noted that, though in a seminal study by Wild et al. [23] average lipid concentrations in women with PCOS were indeed higher than in the general population, but the overall difference was not striking (e. g., LDL cholesterol concentrations were only $9 \mathrm{mg} / \mathrm{dl}$ higher, when matched for BMI) [23]. In a Korean study on women with PCOS [24], there were no differences in the absolute level of LDL-C, mean LDL diameter or percentage of atherogenic sd-LDLs between $\mathrm{PCOS}$ patients and controls or between hyperandrogenic and non-hyperandrogenic PCOS subgroups. 
a

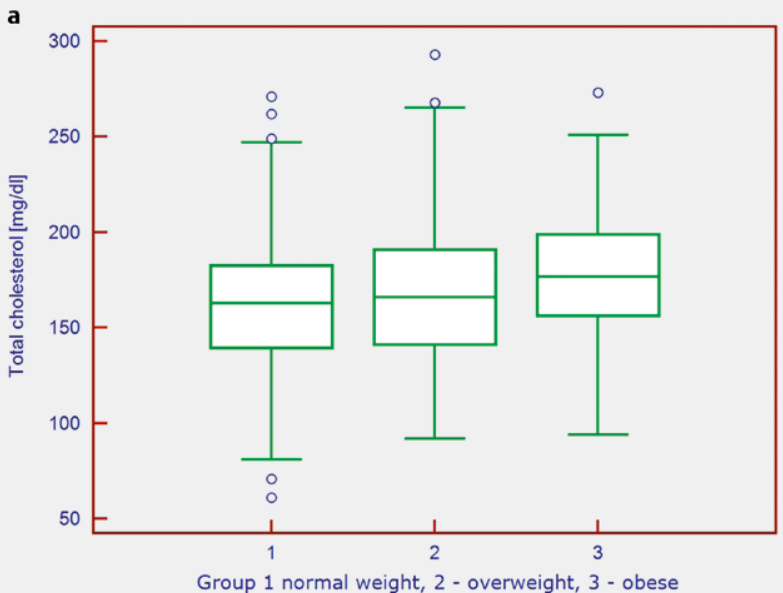

c

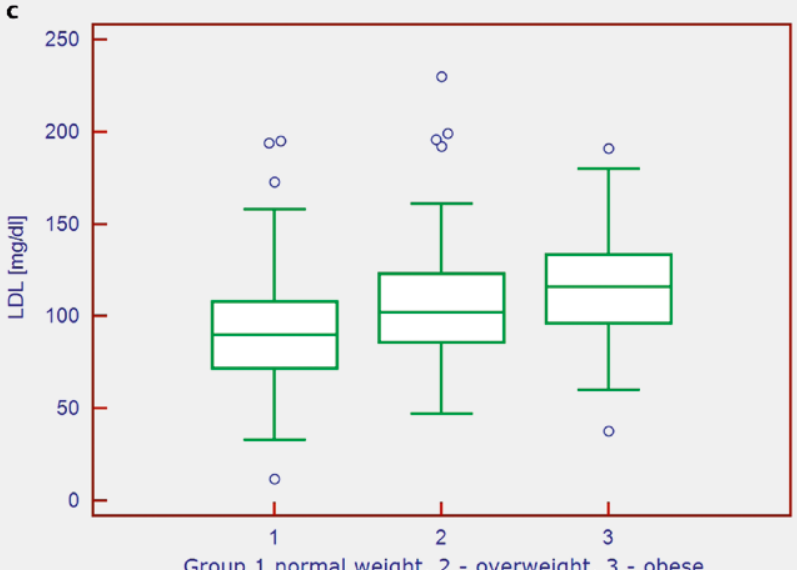

b

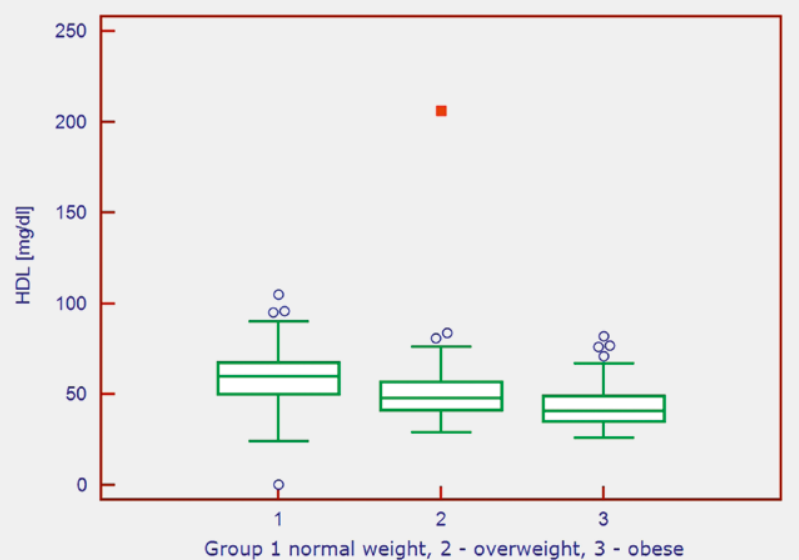

d

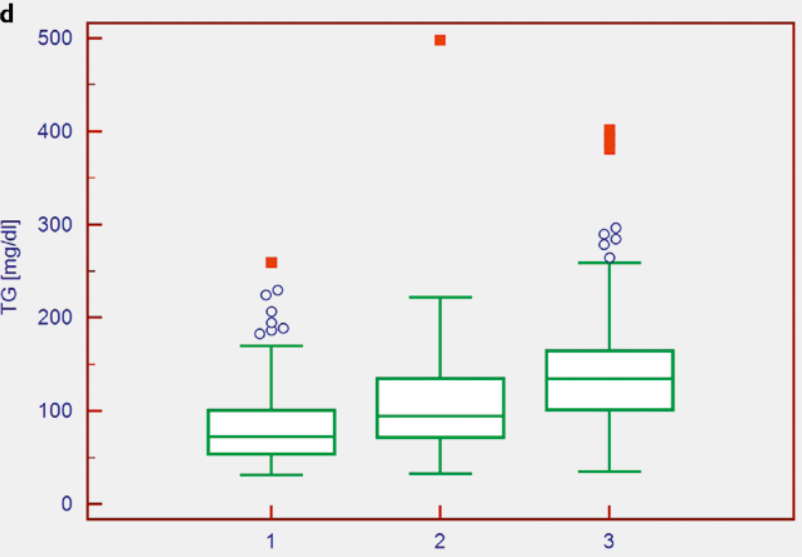

Group 1 normal weight, 2 - overweight, 3 - obese

- Fig. 1 a Total cholesterol distribution in 490 women with PCOS according to BMI, where Group 1 - normal BMI ( $\left.<26 \mathrm{~kg} / \mathrm{m}^{2}\right)$, Group 2 - overweight (BMI $\left.26-30 \mathrm{~kg} / \mathrm{m}^{2}\right)$, and Group 3 - obese $\left(\mathrm{BMI}>30 \mathrm{~kg} / \mathrm{m}^{2}\right)$. There is a tendency towards higher total cholesterol concentrations with increased obesity (one-way ANOVA, $\mathrm{p}<0.05$ ). b HDL cholesterol distribution in 490 women with PCOS according to BMI, where Group $1-$ normal BMI (<26 kg/ $\left.\mathrm{m}^{2}\right)$, Group 2 - overweight (BMI $\left.26-30 \mathrm{~kg} / \mathrm{m}^{2}\right)$, and Group 3 - obese $\left(\mathrm{BMI}>30 \mathrm{~kg} / \mathrm{m}^{2}\right)$. There is a tendency towards lower HDL cholesterol concentrations with increased obesity (one-way ANOVA, $\mathrm{p}<0.05$ ). c LDL cholesterol distribution in 490 women with PCOS according to BMI, where Group 1 - normal BMI $\left(<26 \mathrm{~kg} / \mathrm{m}^{2}\right)$, Group 2 - overweight (BMI $\left.26-30 \mathrm{~kg} / \mathrm{m}^{2}\right)$, and Group 3 - obese $\left(\mathrm{BMI}>30 \mathrm{~kg} / \mathrm{m}^{2}\right)$. There is a tendency towards higher HDL cholesterol concentrations with increased obesity (one-way ANOVA, $\mathrm{p}<0.05$ ). d Triglyceride distribution in 490 women with PCOS according to BMI, where Group 1 - normal BMI $\left(<26 \mathrm{~kg} / \mathrm{m}^{2}\right)$, Group 2 - overweight (BMI $\left.26-30 \mathrm{~kg} / \mathrm{m}^{2}\right)$, and Group 3 - obese (BMI $\left.>30 \mathrm{~kg} / \mathrm{m}^{2}\right)$. There is a tendency towards higher HDL cholesterol concentrations with increased obesity (one-way ANOVA, $\mathrm{p}<0.05$ ).

- Table 2 Correlation of insulin resistance indices (Spearman rank correlation) with lipid and androgen concentrations

\begin{tabular}{|c|c|c|c|c|c|c|c|}
\hline & LDL & HDL & TG & TC & Testosterone & Androstenedione & DHEA-S \\
\hline HOMA & 0.284 & -0.503 & 0.473 & 0.138 & 0.155 & 0.124 & 0.0327 \\
\hline IRI & 0.332 & -0.433 & 0.399 & 0.188 & 0.139 & 0.0536 & 0.0825 \\
\hline QUICKI & -0.286 & 0.500 & -0.472 & -0.141 & -0.152 & -0.124 & -0.0382 \\
\hline McAuley & -0.284 & 0.494 & -0.470 & -0.142 & -0.150 & -0.122 & -0.0358 \\
\hline
\end{tabular}

All significant correlations $(p<0.05)$ are marked in italics. 
- Table 3 Comparison of investigated parameters according to androgen concentrations (i. e., normal or above the reference range)

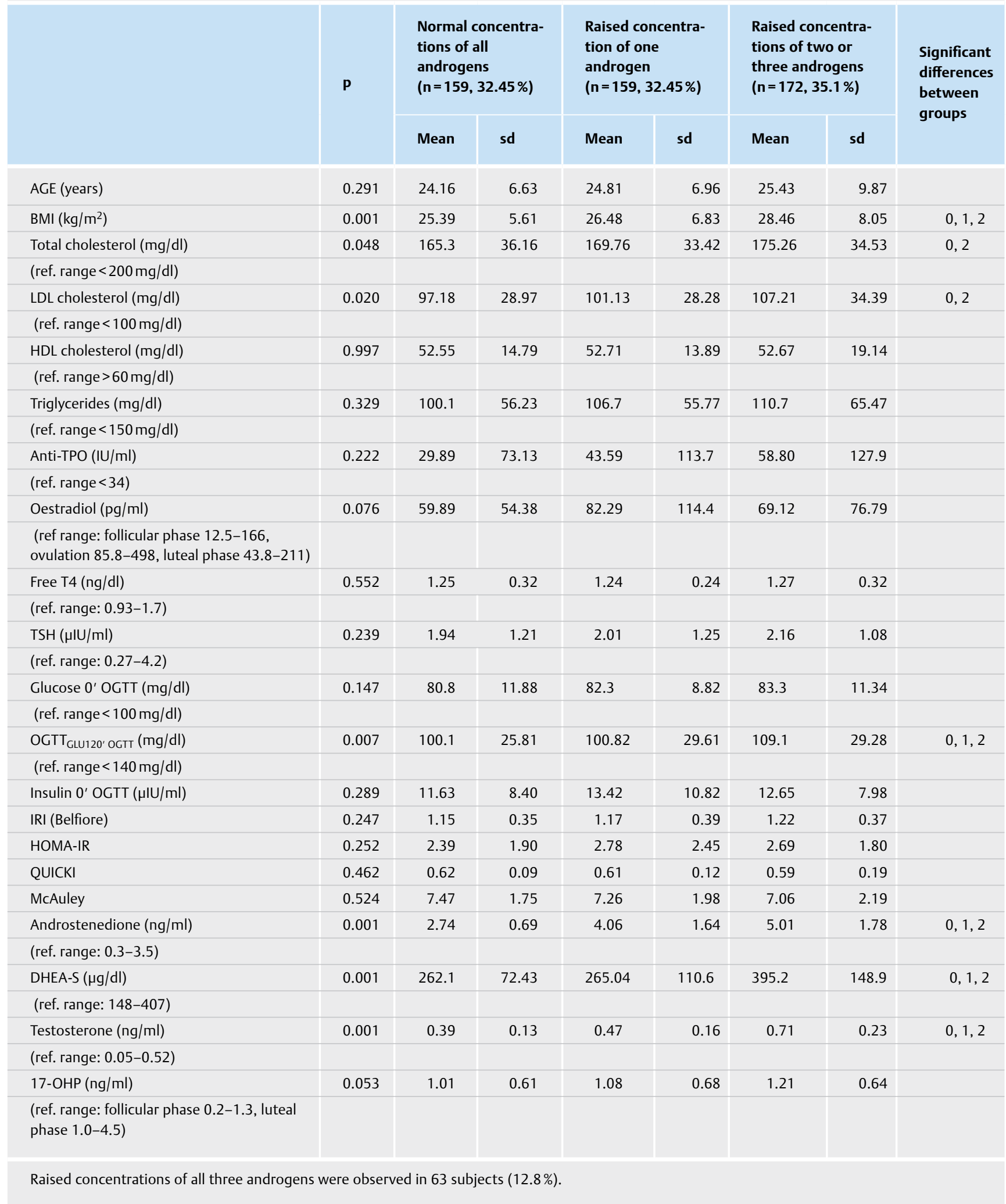

Our study also demonstrated that most women with PCOS (64.9\%, i. e., 318 out of 490$)$, diagnosed according to the Rotterdam criteria, did not have significant hyperandrogenaemia, that is, they have either normal androgen concentrations or just one of the three measured androgens was above the reference range. Taking into account, well known limitations of androgen measurements 
within the female range [25] due low precision of measurements and wide coefficients of variation, it is likely that many women with a single raised androgen concentration, might have normal androgens on repeated testing. Furthermore, there was no difference in any measured parameters between the two groups, while BMI, glucose concentrations at 120 min of OGTT, and lipid parameters seemed to worsen only in women with more "severe" phenotype, that is, those with raised concentrations of at least 2 androgens. It should be noted, however, that even in that group mean lipid concentrations and glucose levels were still within the reference range, with exception of HDL cholesterol. According to the Rotterdam criteria women with PCOS can be also divided into 4 major phenotypes: (1) frank PCOS (oligomenorrhea, hyperandrogenism, and PCO), (2) ovulatory PCOS (hyperandrogenism, PCO, and regular menstrual cycles), (3) non-PCO PCOS (oligomenorrhea, hyperandrogenism, and normal ovaries), and (4) the mildest phenotype characterised by oligomenorrhea, PCO, and normal androgens [6]. Though highly desired, our retrospective analysis did not allow us to precisely divide our patients according to the four PCOS phenotypes. It should be noted, however, that phenotype 2 was very uncommon, as women with regular periods are rarely referred for hospital assessment, while all women with normal androgens (33\%), and likely a significant part of women with borderline increase of a single androgen only, can be considered to represent the mildest fourth phenotype that appears to be the most prevalent form among our PCOS population.

Our data showing a worsening of metabolic phenotype with increasing androgenaemia, are in keeping with the results of a recent British study of O'Reilly et al. [26]. Interestingly, the authors of the above study showed that serum androstenedione was a more sensitive indicator of PCOS-related androgen excess than serum total testosterone concentrations [26]. Despite these data there is, however, still no clear evidence that hyperandrogenaemia per se is linked to an increased cardiovascular mortality. For instance, in a large ( $n=2578)$ prospective population-based study in postmenopausal women from Rotterdam municipality, who had been free of cardiovascular disease at study entry, there was no association between higher androgen levels and incident stroke, coronary heart disease or composite cardiovascular events, after adjustment for other cardiovascular risk factors [27]. Interestingly in our study there was also no significant increase in insulin resistance indices, despite increasing androgenaemia. Detailed information on aspects related to assessment of insulin resistance in our PCOS subjects has been already presented [28].

In our opinion, clearly there is a subgroup of women with PCOS with significant hypernadrogenaemia and insulin resistance, who have an increased cardiovascular risk. On the other hand, however, if PCOS is diagnosed according to the Rotterdam criteria, then this diagnosis is established also in a large group of women with milder metabolic phenotype, who might not have a particularly increased risk of cardiovascular disease in comparison to the general population. Hence, a lack of an unequivocal evidence for an increased cardiovascular risk in PCOS has been confirmed in a recent review by Stunden and Pfeifer [29]. In a recent meta-analysis on the risk of metabolic syndrome in PCOS [30], the authors demonstrated that there is a significant increase in the odds of metabolic syndrome in adolescents with PCOS in comparison to heathy ado- lescent controls. On the other hand in older (i. e., adult subjects) there was no difference in the odds of metabolic syndrome in women with PCOS in comparison to healthy controls in population-based studies, particularly after BMI adjustment. These results are in keeping with our data, where in multivariate analysis, the body mass index, was the principal determinant of an adverse cardiovascular profile. Also in keeping with our data, the authors of the above meta-analysis [30] demonstrated that the odds of metabolic syndrome were higher in women with PCOS diagnosed according to the National Institutes of Health criteria, in comparison to the Rotterdam consensus criteria.

There is also evidence that the severe phenotype of PCOS, as an important factor for the risk of metabolic syndrome may improve with increasing age [31]. In this regard, production of androgen may be reduced across time due to limited adrenal secretion and ovarian aging [32]. Consequently, the prevalence of androgen-dependent complications, such as hirsutism, acne and glucose intolerance may decrease with age in women with PCOS, contrasting with increase of the prevalence of metabolic syndrome in general population due a well-known phenomenon of an age-related increase in mean BMI [33].

In summary, we have demonstrated that application of the Rotterdam consensus criteria for the diagnosis of polycystic ovary syndrome results in a situation where half of women with PCOS have normal BMI and the majority have normal lipid concentrations. Also approximately two third of women have either normal or borderline androgen concentrations. Hence, population of women with polycystic ovary syndrome, diagnosed according to the Rotterdam consensus criteria appears to be dominated by women with the mildest phenotype, which seems not to be associated with an increased cardiovascular risk. Though there is a subgroup of women with markedly abnormal metabolic profile, this seems "diluted" in the whole population of women with PCOS, thus likely leading to the lack of an overall increase in mortality. A prospective study might be considered, where cardiovascular risk factors in women with PCOS are assessed predominantly in phenotypes linked with significant hyperandrogenism.

\section{Conflict of Interest}

The authors declare that they have no conflict of interest.

\section{References}

[1] Azziz R. Polycystic ovary syndrome. Obstet Gynecol 2018; 132: 321-336

[2] Teede H], Misso ML, Costello MF et al. Recommendations from the international evidence-based guideline for the assessment and management of polycystic ovary syndrome. Clin Endocrinol (Oxf) 2018; 89: 251-268

[3] Milewicz A, Kudła M, Spaczyński RZ et al. The polycystic ovary syndrome: a position statement from the Polish Society of Endocrinology, the Polish Society of Gynaecologists and Obstetricians, and the Polish Society of Gynaecological Endocrinology. Endokrynol Pol 2018; 69: 328-344 
[4] Gunning MN, Fauser CJM. Are women with polycystic ovary syndrome at increased cardiovascular disease risk later in life. Climacteric 2017; 20: $222-227$

[5] Jacewicz-Święcka M, Kowalska I. Polycystic ovary syndrome and the risk of cardiometabolic complications in longitudinal studies. Diabetes Metab Res Rev 2018; 34: e3054

[6] The Rotterdam ESHRE/ASRM-sponsored PCOS Consensus Workshop Group. 2004; Revised 2003 consensus on diagnostic criteria and long-term health risks related to polycystic ovary syndrome (PCOS). Hum Reprod 2004; 19: 41-47

[7] Belfiore F, lannello S, Volpicelli G. Insulin sensitivity indices calculated from basal and OGTT-induced insulin, glucose, and FFA levels. Mol Genet Metab 1998; 63: 134-141

[8] Matthews DR, Hosker JP, Rudenski AS et al. Homeostasis model assessment: insulin resistance and beta-cell function from fasting plasma glucose and insulin concentrations in man. Diabetologia 1985; 28: 412-419

[9] Katz A, Nambi SS, Mather K et al. Quantitative insulin sensitivity check index: A simple, accurate method for assessing insulin sensitivity in humans. J Clin Endocrinol Metab 2000; 85: 2402-2410

[10] McAuley KA, Williams SM, Mann Jl et al. Diagnosing insulin resistance in the general population. Diabetes Care 2001; 24: 460-464

[11] Jellinger PS, Smith DA, Mehta AE et al. American Association of Clinical Endocrinologists' guidelines for management of dyslipidemia and prevention of atherosclerosis. Endocrine Pract 2012; 18: (Suppl 1) 1-78

[12] Araszkiewicz A, Bandurska-Stankiewicz E, Budzyński A et al. Guidelines on the management of diabetic patients. A position of Diabetes Poland. Diabetol Klin 2016; 5: (Suppl A) A1-A73

[13] Azziz R, Woods KS, Reyna R et al. The prevalence and features of the polycystic ovary syndrome in an unselected population. J Clin Endocrinol Metab 2004; 89: 2745-2749

[14] Welt CK, Carmina E. Clinical review: Lifecycle of polycystic ovary syndrome (PCOS): From in utero to menopause. J Clin Endocrinol Metab 2013; 98: 4629-4638

[15] Bajuk Studen K, Jensterle Sever M, Pfeifer M. Cardiovascular risk and subclinical cardiovascular disease in polycystic ovary syndrome. Front Horm Res 2013; 40: 64-82

[16] Orio F Jr., Palomba S, Spinelli L et al. The cardiovascular risk of young women with polycystic ovary syndrome: an observational, analytical, prospective case control study. J Clin Endocrinol Metab 2004; 89: 3696-3701

[17] Hart R, Doherty DA. The potential implications of a PCOS diagnosis on a woman's long-term health using data linkage. J Clin Endocrinol Metab 2015; 100: 911-919
[18] Pierpoint T, McKeigue PM, Isaacs AJ et al. Mortality of women with polycystic ovary syndrome at long-term follow-up. J Clin Epidemiol 1998; 51: 581-586

[19] Wild S, Pierpoint T, McKeigue P et al. Cardiovascular disease in women with polycystic ovary syndrome at long-term follow-up: A retrospective cohort study. Clin Endocrinol (Oxf) 2000; 52: 595-600

[20] Peigné M, Dewailly D. Long term complications of polycystic ovary syndrome (PCOS). Ann Endocrinol (Paris) 2014; 75: 194-199

[21] Kakoly NS, Khomami MB, Joham AE et al. Ethnicity, obesity and the prevalence of impaired glucose tolerance and type 2 diabetes in PCOS: A systematic review and meta-regression. Hum Reprod Update 2018; 24: $455-467$

[22] Pelanis R, Mellembakken JR, Sundström-Poromaa I et al. The prevalence of type 2 diabetes is not increased in normal-weight women with PCOS. Hum Reprod 2017; 32: 2279-2286

[23] Wild RA, Rizzo M, Clifton S et al. Lipid levels in polycystic ovary syndrome: Systematic review and metaanalysis. Fertil Steril 2011; 95: 1073-1079 e1-e11

[24] Kim J], Choi YM. Dyslipidemia in polycystic ovary syndrome. Obstetr Gynecol Sci 2013; 56: 137-142

[25] Barth J, Yasmin E, Balen AH. The diagnosis of polycystic ovary syndrome: the criteria are insufficiently robust for clinical research. Clin Endocrinol 2007; 67: 811-815

[26] O'Reilly MW, Taylor AE, Crabtree N] et al. Hyperandrogenemia predicts metabolic phenotype in polycystic ovary syndrome: The utility of serum androstenedione. J Clin Endocrinol Metab 2014; 99: 1027-1036

[27] Meun C, Ranco OH, Dhana K et al. High androgens in postmenopausal women and the risk for atherosclerosis and cardiovascular disease. J Clin Endocrinol Metab 2018; 103: 1622-1630

[28] Lewandowski KC, Płusajska J, Horzelski W et al. Limitations of insulin resistance assessment in polycystic ovary syndrome. Endocr Connect 2018; 7: 403-412

[29] Stunden KB, Pfeifer M. Cardiometabolic risk in polycystic ovary syndrome. Endocrine Connect 2018; 7: R238-R251

[30] Behboudi-Gandevani S, Amiri M, Yarandi RB et al. The risk of metabolic syndrome in polycystic ovary syndrome: A systematic review and meta-analysis. Clin Endocrinol (Oxf) 2018; 88: 169-184

[31] Hsu MI. Changes in the PCOS phenotype with age. Steroids 2013; 78 : 761-766

[32] Ding EL, Song Y, Manson JE et al. Plasma sex steroid hormones and risk of developing type 2 diabetes in women : A prospective study. Diabetologia 2007; 50: 2076-2084

[33] Brown ZA, Louwers YV, Fong SL et al. The phenotype of polycystic ovary syndrome ameliorates with aging. Fertil Steril 2011; 96: 1259-1265 